Review

\title{
Engineered exosomes: A new promise for the management of musculoskeletal diseases
}

\author{
Bellavia D. ${ }^{\mathrm{a}, \mathrm{b}, *}$, Raimondi L. ${ }^{\mathrm{a}, \mathrm{b}}$, Costa V. ${ }^{\mathrm{a}, \mathrm{b}}$, De Luca A. ${ }^{\mathrm{a}, \mathrm{b}}$, Carina V. ${ }^{\mathrm{a}, \mathrm{b}}$, Maglio M. ${ }^{\mathrm{c}}$, Fini M. ${ }^{\mathrm{c}}$, \\ Alessandro R. ${ }^{\text {d,e }}$, Giavaresi G. ${ }^{\text {b,c }}$ \\ a Rizzoli Orthopaedic Institute, Bologna, Italy \\ ${ }^{\mathrm{b}}$ Rizzoli Orthopaedic Institute, Innovative Technology Platforms for Tissue Engineering, Theranostics and Oncology, Palermo, Italy \\ ${ }^{\mathrm{c}}$ Rizzoli Orthopaedic Institute, Laboratory of Preclinical and Surgical Studies, Bologna, Italy \\ d Department of Biopathology and Medical Biotechnologies, Section of Biology and Genetics, University of Palermo, Palermo 90133, Italy \\ $\mathrm{e}$ Institute of Biomedicine and Molecular Immunology (IBIM), National Research Council, Palermo, Italy.
}

\section{A R T I C L E I N F O}

\section{Keywords:}

Engineered exosomes

Drug delivery

Musculoskeletal diseases

Regenerative medicine

Oncology

Immune system regulation

\begin{abstract}
A B S T R A C T
Background: Exosomes are nanovesicles actively secreted by potentially all cell types, including tumour cells, with the primary role of extracellular systemic communication mediators, both at autocrine and paracrine levels, at short and long distances. Recently, different studies have used exosomes as a delivery system for a plethora of different molecules, such as drugs, microRNAs and proteins. This has been made possible thanks to the simplicity in exosomes engineering, their great stability and versatility for applications in oncology as well as in regenerative medicine.

Scope of review: The aim of this review is to provide information on the state-of-the-art and possible applications of engineered exosomes, both for cargo and specific cell-targeting, in different pathologies related to the musculoskeletal system.

Major conclusions: The use of exosomes as therapeutic agents is rapidly evolving, different studies explore drug delivery with exosomes using different molecules, showing an enormous potential in various research fields such as oncology and regenerative medicine.

General significance: However, despite the significant progress made by the different studies carried out, currently, the use of exosomes is not a therapeutic reality for the considerable difficulties to overcome.
\end{abstract}

\section{Introduction}

The development of new procedures for cellular-specific treatments have opened new possibilities for the delivery of different molecules involved in regenerative medicine and oncology. Recently, exosomes have emerged as potent cell-free delivery tools, thanks to their high physicochemical stability and biocompatibility $[1,2]$, together with the lack of potentially dangerous effects derived from viable cell administration [3].

In fact, the use of viable cells can induce the development of autoimmune reactions or rejection of injected cells, increased cancer risk or occlusions of the micro-vasculatures and risks of persistent and amplified stimulation also after disease resolution. [3]. In addition, injected cells can move towards erroneous differentiation, leading to potentially deleterious effects, as reported by Breitbach et al. [4]. These authors described that injected mesenchymal stem cells (MSCs) for myocardial regeneration determined ectopic ossifications and/or calcifications in a murine model of myocardial infarctions.

The risks associated with exosome therapies are rather small compared to therapies with modified cells, making exosomes ideal nanocarriers for clinical applications. In addition, their ability to directly communicate with target cells makes them far preferable to other

\footnotetext{
Abbreviations: 3’UTR, 3'untranslated regions; 6-OHDA, 6-hydroxydopamine; APC, adenomatous polyposis coli; BRD7, bromo-domain-containing protein 7; CML, chronic myeloid leukemia; CNS, Central Nervous System; CXCL12, CXC Motif Chemokine Ligand 12; DC, Dendritic cell; ECM, extracellular matrix; EGFR, epidermal growth factor receptor; EMT, Epithelial-Mesenchymal Transition; ESCRT, Endosomal Sorting Complexes Required for Transport; GSK-3ß, glycogen synthase kinase 3 beta; hBMMSCs, human Bone Marrow-Derived Mesenchymal Stem Cells; hESCs, human Embryonic Stem Cells; hMSCs, human Mesenchymal Stem Cells; HUVECs, Human Umbilical-Vein Endothelial Cells; Lamp, Lysosome-associated membrane glycoproteins; LATS2, large tumour suppressor kinase 2; lncRNAs, long non-coding RNAs; LPS, lipopolysaccharide; mDCs, mouse Dendritic Cells; MHC, major histocompatibility complex; miRNAs, micro RNA; MVB, multivesicular bodies; OBs, osteoblasts; OCs, osteoclasts; ROS, reactive oxygen species; Runx-2, runt-related transcription factor 2; siRNAs, short interference RNA; SOX, Sex-determining Region Y -related High Mobility Group box; VEGF, Vascular endothelial growth factor

* Corresponding author at: Innovative Technology Platforms for Tissue Engineering, Theranostics and Oncology, Rizzoli Orthopaedic Institute, Via Divisi, 83,90133 Palermo, Italy E-mail address: daniele.bellavia@ior.it (D. Bellavia).
} 
delivery formulations, which can carry risks of toxicity or rapid clearance. In fact, some pre-clinical in vivo studies showed that the use of targeted exosomes to specific cells can reduce the concentration of transported molecules administered, achieving the same effect of systemic treatments and avoiding their short- and long-term side effects that, for some drugs, are extremely harmful.

Despite the increasing interest in these carriers, no specific regulatory requirements for pharmaceutical manufacturing and clinical application are present so far. It is however undeniable that their production should be carried out in specific well-organized structures, strictly following GxP standards ( $\mathrm{GxP}=\mathrm{Good}$ Manufacturing/Good Laboratory/Good Distribution/Good Clinical/Good Scientific Practice or GMP/GLP/GDP/GCP/GSP), to limit any possible contamination and taking into account both donor and recipient safety $[5,6]$.

The aim of the present review is to summarize the state-of-art on the use of modified exosomes used as natural nanoparticles to deliver different molecules as therapeutic agents in regenerative medicine, oncology and other orthopaedic pathologies, highlighting the most recent therapeutic uses and possible new applications.

\section{Search strategy}

The following literature research was carried out in the MEDLINE database (PubMed research engine): (((exosome?) OR exosomes [MeSH Terms]) AND (((engineering) OR engineered) OR targeted)), by considering articles with abstract in English (AND "English" [language]) and published after January 1, 2010 (AND ("2010/01/01"[Date Entrez]: "2017/09/30"[Date - Entrez])). This search retrieved 713 articles. Reviews (NOT Review [Publication Type]) were then excluded, reducing the number of collected articles to 506. Three reviewers manually assessed the title and abstract of collected references and those not considered pertinent were excluded. Finally, 147 articles related to the topics of our interest (bone, cartilage and musculoskeletal diseases) were selected, but articles already cited in others were not included, obtaining 72 studies. In addition to the selected articles, further 47 studies were added being considered of interest in the final review and to add information on some technical aspects (Fig. 1).

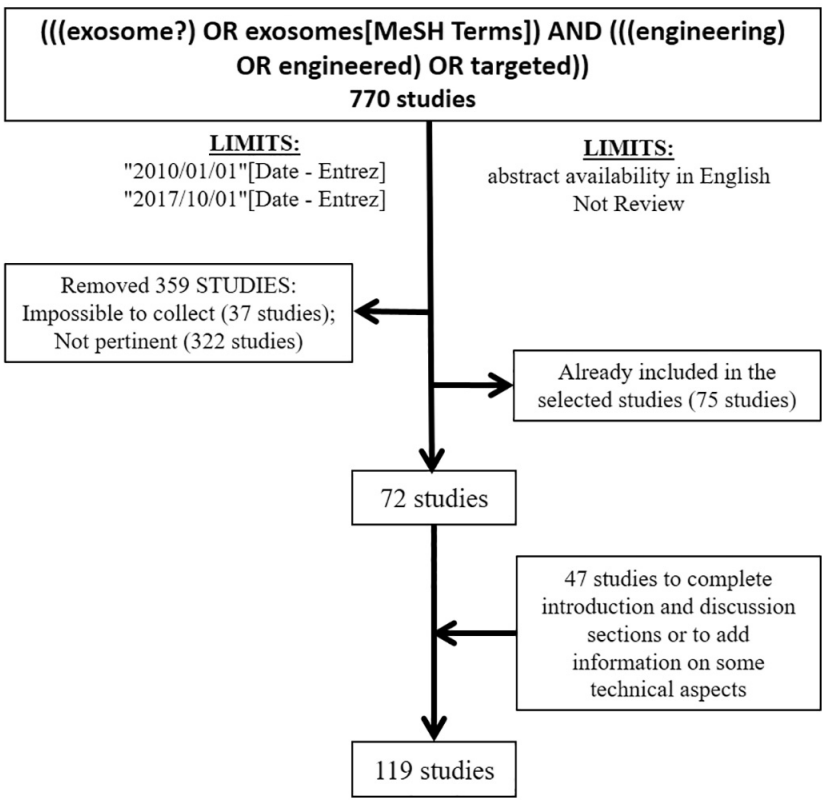

Fig. 1. Diagram of the reference search strategy and selection.

\section{Exosomes: characteristics and potentialities}

Exosomes are small bi-layered vesicles with a diameter of 40-100 nm, produced by almost all cell types, both in physiological and pathological state, within the endo-lysosomal compartment and released with the exocytosis of multivesicular bodies (MVB). Initially identified as cellular garbage vehicles, removing a variety of molecules like unnecessary proteins, in the past 15 years, exosomes emerged as important intercellular communication systems, working at very short and long distance [7].

Most common isolation method of exosomes, from conditioned medium (CM) of source cells, is based on:

1) differential centrifugation of CM to remove intact cells, cellular debris and other big contaminants; and 2) ultracentrifugation on sucrose gradient to remove contaminating material in the exosome pellet such as protein aggregates or other microvesicles (as macromolecules as apoptotic bodies or microvesicles that originates from plasmatic membrane) due to different flotation of this macromolecules respect to exosomes [7].

Protein content of exosomes represents an aspect of particular interest, consisting of proteins related to the source cell type, reflecting its pathological or physiological status at the time of micro-vesicles formation [8, 9], as well as the so called "exosomal markers". These proteins, related to exosomes biogenesis, include Alix, Lysosome-associated membrane glycoproteins (Lamp 1, 2 and 3), Tetraspanins (CD9, CD63, CD81, CD82, and CD151) and Endosomal Sorting Complexes Required for Transport (ESCRT) machinery [10, 11] (Fig. 2). In addition, other proteins are usually displayed in the exosomes such as major histocompatibility complex (MHC) proteins, which exhibit surface antigens stimulating the immune system [12], soluble and membrane morphogens, implicated in cell differentiation and tissue regeneration $[13,14]$, and other surface proteins present in exosomal membrane that confer a specific tropism to target cells [15]. For example, cancer cells are able to interact with stromal cells through exosomes release, which induce local differentiation of fibroblasts and neovascularization to support tumour growth [16]. In addition, other studies showed that the presence of surface integrins in exosomes membranes, such as $\alpha 6 \beta 4$, $\alpha 6 \beta 1$ or $\alpha v \beta 5$, promote tumour exosome spreading in different tissue (lung or liver) to prepare the appropriate environment for tumour colonization [17].

Particular interest was given to the RNA content of these nanovesicles, which differ significantly, both quantitatively and qualitatively, from the total RNA of the source cells, suggesting an active, regulated and selective loading, as reported in literature [18-22]. Exosomes lack intact ribosomal RNA and are rich of non-coding RNA and, as micro RNA (miRNA) and long non-coding RNAs (lncRNAs), which can modulate cell viability interfering in different cellular pathways in targeted cells $[23,24]$. Although the activity of other exosomal factors cannot be excluded, miRNAs specifically seem to play a pivotal role in exosomemediated biological functions [24]. The peculiar characteristics of exosomal RNA, in particular their greater stability in comparison to cellular RNAs, make them interesting for RNA-based in vivo therapies, which still suffers from lack of appropriate delivery systems [25].

Exosomes cargo can be internalized via endocytosis, pinocytosis and direct fusion with plasma membrane, which lead to different actions and fates of cargo itself (Fig. 3). For example, modifications in exosomal membrane can occur, conferring the ability of cell selection and internalization in target cells [26, 27]. For their characteristics, such as stability in all bodily fluids [28], specific tropism to target cells or tissues [17], ability to pass easily through biological barriers, exosomes are emerging as system for delivery of different molecules and represent a powerful therapeutic tool for numerous diseases.

Strategies to modify exosomes for application as carriers can be very different and require modifications of source cells or exosomes directly. Expression vector can be used to induce overexpression of proteins or noncoding RNA into cells, packaged into nanovesicles to obtain the 


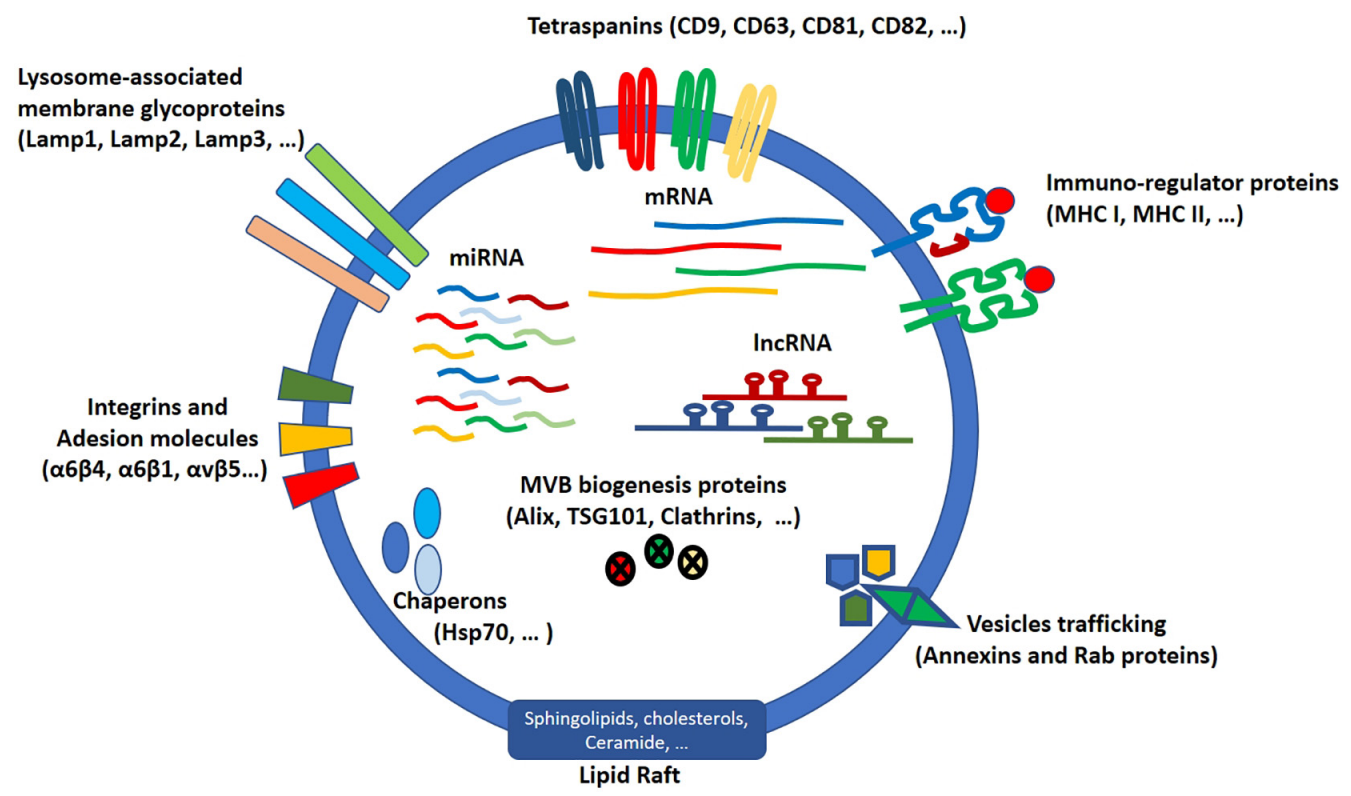

Fig. 2. Schematic representation of an exosome and its content.

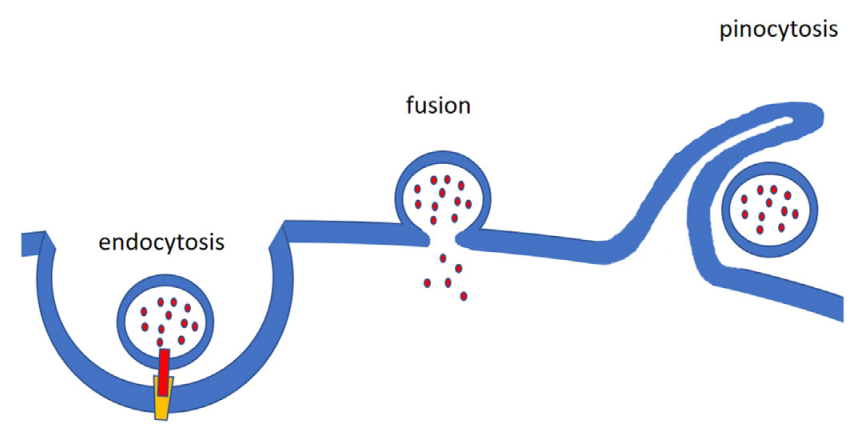

Fig. 3. Schematic draw of the various exosome uptake mechanisms.

specific delivery of cargo or regulate the transcription in target cells [29-34]. Exogenous material, such as short interference RNA (siRNAs) or drugs, may be naturally internalized into exosomes through the direct treatment of exosome source cells, which subsequently release them by exocytosis. Alternatively, the exogenous material may be transfected directly into the exosomes [31-36]. For example, a direct exosomal modification strategy is to permeabilize isolated microvesicles to allow loading of different molecules into the exosomes. A similar approach uses lipophilic or amphipathic molecules to mark exosomal membrane with the phospholipid bilayer [37] (Fig. 4).

Chemical reactions may also be performed directly on the vesicle membrane. For instance, carbodiimides can be used to modify native amines in order to present azide groups to trigger chemistry reactions. Modified exosomes are initially used as drug delivery system, where these vesicles are charged with chemotherapeutic molecules or specific siRNA to induce inhibition of tumour growth. Additionally, these exosomes can be engineered with a fusion protein to create a specific tropism to tumour cells [29, 30, 32-34]. For example, Alvarez-Erviti et al. created, for the first time, a fusion protein between murine Lamp2b, an exosomal membrane protein, with neuron-specific RVG peptide. Exosomes with this engineered protein has an intrinsic ability to target neuronal cells [29]. In our laboratory, we have engineered human Lamp2B, adding Interleukin 3 epitope. Exosomes with this protein show to bind selectively to chronic myeloid leukemia cells [34].

Engineered exosomes were explored in the musculoskeletal field and their use has been applied to regenerative medicine (nervous system, cartilage and bone regeneration) and regulation of immune system (stimulation and/or repression in different pathologies), while their application in oncology is still at the beginning phases.

\section{Exosomes in regenerative medicine}

In this section, we discuss the reviewed studies on exosomes applications in regenerative medicine for muscular-skeletal pathologies, summarized in Table 1.

\subsection{Exosomes in regenerative process}

In the last decades, treatment protocols for regenerative medicine have been extensively enriched with the use of stem cells, thanks to their capability to differentiate towards different lineage under specific stimuli, accelerating and improving tissue healing [37, 38]. However, many aspects of the mechanisms of action underlying this process are still under debate. In literature, there are indications that the regenerative effect of stem cells might be related to a paracrine activity and not merely to the effective differentiation of these cells directly into the damaged tissue. This is also suggested by evidence that only a small number of locally or systemically injected stem cells integrate into the damaged tissue [39]. In any case, the paracrine activity can explain only in part the regenerative effects of stem cells. Indeed, it is more and more evident that there are many actors in the repair process, from circulating cells to tissue resident cells, and that a key role is played by the active communication between these cell population through different mechanisms, including exosomes.

The involvement of exosomes on the regenerative process has been highlighted in many papers, investigating the effect of exosomes from different cell types on various tissues and organs. The cell types include MSCs of different origins (i.e. bone marrow and adipose tissue), hematopoietic stem cells, progenitor of endothelial cells, embryonic stem cells, and well differentiated cells such as dendritic cells (DC), or immune system cells (monocytes, macrophages, B- and T-cells). Exosomes source cells can be loaded with different molecules that enhance or inhibit specific factors in target cells, thus modulating the regeneration rate [40].

From an overview of the articles on exosomes in regenerative medicine emerges a prevalence of studies related to Central Nervous 


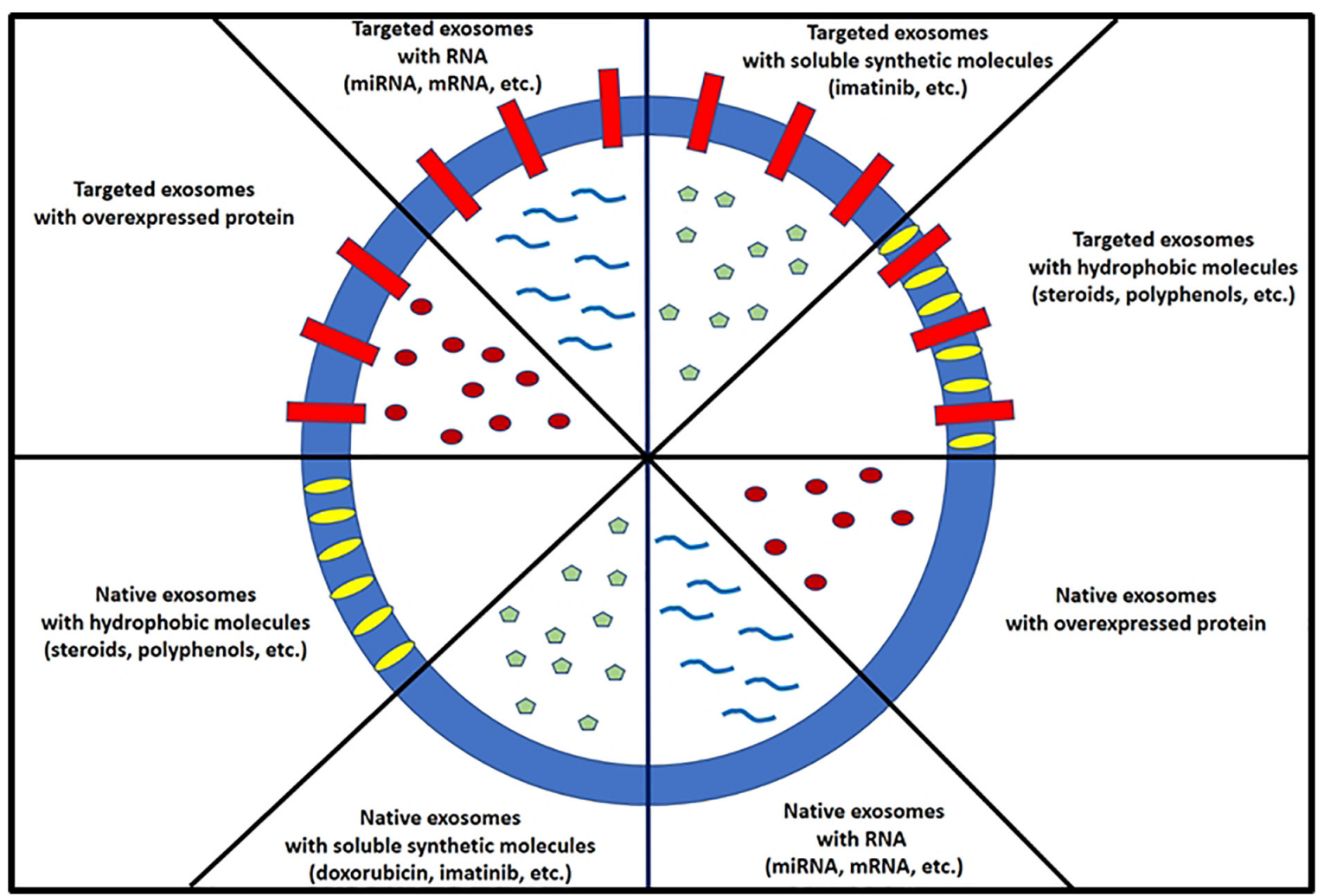

Fig. 4. Schematic draw of different types of content in native or engineered exosomes.

System (CNS) injuries [41, 42], cardiovascular disease [43-45], or kidney injury [46-49] and the extensive exploitation of exosomes immune regulation activities on target cells. In fact, inflammation status influences the regeneration rate, since proinflammatory cytokines can activate different pathways determining poor tissue regeneration and the formation of fibrous scars.

\subsection{Exosomes in bone and cartilage regeneration}

In the field of bone regeneration, great attention is given to MSCsderived exosomes for their capability to influence bone formation, interacting with bone microenvironment at different levels [50]. Bone regeneration is a temporal and spatial concerted regulation of the activity of different cell types, such as osteoblasts (OBs), osteoclasts (OCs), osteocytes, chondrocytes, and endothelial cells, which communicate through different mechanisms. MSCs-derived exosomes can generally induce OBs differentiation through the delivery of different miRNA cargos [51-53], but recent in vitro and in vivo studies suggest that this effect seems to be improved by a previous commitment of MSCs towards osteoblastic lineage [52, 54-56]. In particular, Narayanan et al. indicated that exosomes produced by already committed cells were able to bind to the extracellular matrix (ECM) and induce osteoblastic differentiation of all cells they locally interact with [52]. In addition, considering the importance of the cross-talk between OCs and OBs in bone homeostasis, targeting specific molecules to inhibit or promote osteoblastogenesis, like miR-214-3p in OCs, is of great interest, as suggested by a recent work by Li et al. [57]. Moreover, other bone cell populations, like immune and hematopoietic cells and their exosomes, have a strong influence in bone and cartilage regeneration by means of their roles in inflammation. For example, in a lipopolysaccharide (LPS) induced inflammation model, monocytes produce exosomes with enhanced pro-osteogenic differentiation [58, 59].

Table 1

Published studies on application of exosomes in regenerative medicine.

\begin{tabular}{|c|c|c|c|c|}
\hline Source cell & Target cell & Modification & Actions & Reference \\
\hline hMSCs & Neurons & Lentiviral vector expressing miR-133b in source cells & Nerve regeneration & [41] \\
\hline Mouse macrophage (RAW 264.7) & CNS environment & Plasmid vector expressing catalase in source cells & Brain inflammation reduction & [42] \\
\hline hBMMSCs & hBMMSCs & Osteogenic medium treatment of source cells & Osteoblastogenesis induction & [52] \\
\hline hBMMSCs & hBMMSCs & Plasmid for overexpression of Runx2 in source cells & Osteoblastogenesis induction & [54] \\
\hline Pre-osteoblast cells (MC3T3-E1 cells) & $\begin{array}{l}\text { Bone marrow stromal cells } \\
\text { (ST2 Cells) }\end{array}$ & Osteogenic medium treatment of source cells & Osteoblastogenesis induction & [55] \\
\hline Human monocytes & hMSCs & Native exosomes with no specific regenerative activities & Osteoblastogenesis induction & [59] \\
\hline hESCs & Intra-articular environment & Native exosomes with no specific regenerative activities & Osteochondral regeneration & [63] \\
\hline hMSCs & $\begin{array}{l}\text { mouse C2C12 myoblast cells } \\
\text { HUVECs }\end{array}$ & Transfection of miR-494 in source cells & $\begin{array}{l}\text { Skeletal muscle regeneration } \\
\text { Angiogenesis }\end{array}$ & [69] \\
\hline
\end{tabular}

Abbreviation: CNS - Central Nervous System; hBMMSCs - human Bone Marrow Derived Mesenchymal Stem Cells; hESCs - human Embryonic Stem Cells; hMSCs = human Mesenchymal Stem Cells; HUVECs = Human Umbilical-Vein Endothelial Cells; mDCs = mouse Dendritic Cells. 
On the front of articular cartilage regeneration, current treatments such as mosaicplasty and autologous chondrocytes implantation, still present drawbacks, like donor site morbidity, and often generate low quality fibrocartilage repair. Cell therapies based on MSCs have shown promising results in cartilage regeneration in many studies, where cells paracrine effect seems more and more evident [60-63]. Zhang et al. [63] demonstrated that MSCs exosomes have high power of regeneration of osteochondral defects in a rat model and data are supported by other evidence of the involvement of exosomal miRNAs in this regeneration process. In particular, it seems that different miRNA, enriched in MSCs exosomes, exert beneficial effects on cartilage regeneration, inducing miR-92a and could be used as therapeutic agents against osteoarthritis for their regulatory roles in proliferation and chondrogenic differentiation [64]. Tolerogenic properties of Dendritic Cell-derived exosomes can be increased by overexpressing IL-10, IL-4, or FasL in source cells, generating exosomes able to reduce inflammation in induced arthritis mouse models $[65,66]$.

\subsection{Exosomes in muscle regeneration}

Recently, the use of MSCs secretome and, in particular, of MSCderived exosomes for muscle regeneration was investigated [67-69]. In vivo studies demonstrated that MSCs-derived exosomes were able to accelerate muscle regeneration by increasing angiogenesis and reducing fibrosis [69]. In addition, other studies identified different miRNAs associated with antiapoptotic (miR-21) [67] and myogenic (miR-1, miR-133, miR-206 and miR-494) activities, which could be delivered by specific MSCs engineered exosomes to injured muscles in a skeletal muscle injury rat model [68]. Nakamura et al. highlighted the strategic role of exosomes in the regeneration process and, in particular, of miRNA, identifying the role of not- and well-characterized miRNA. Although the studies on exosomes activities on muscle regeneration are incompletely understood, modified MSCs-derived exosomes with enhanced myo-regenerative effects might be a new therapeutic tool for muscle injury [69].

\subsection{Exosomes in nervous system repair}

Exosomes were also tested in regenerative medicine of the central and peripheral nervous system, being able to cross the blood-brain barrier as well as to modulate inflammatory response, with positive effects on regeneration rates [41, 70]. Nervous system injuries and degenerations are highly debilitating for patients, often resulting in significant musculoskeletal impairments and their management is still demanding and often not resolutive.

Peripheral nerve injuries determine an inflammatory state leading to lack of neuronal functions and consequent neuronal degeneration, cell death and formation of permanent scarring. As previously mentioned, MSCs support nerve growth also through paracrine effects such as secretion of neurovascular factors (as VEGF), and supporting Schwann cells, which are critical for nerve myelination. Several in vivo studies that used different types of bioactive polymers, such as collagen type 1 and hyaluronic acids, for MSCs scaffold, showed enhanced and accelerated nerve regeneration in mouse model after nerve transection. [71-75].

It is reported that MSCs exosomes are able to induce nerve regeneration and the key role is played by miR-133b they contain. MSCsderived exosomes, modified with lentiviral expression vector, determining overexpression or silencing of miR-133b, can respectively induce or repress neurite regeneration, as indicated by the number and length of neurites [41]. Xin et al. hypothesized that MSCs-derived exosomes might be used for the delivery of other functional miRNAs, similarly to miR-133b, for the treatment of nerve diseases where regeneration processes are involved [41].

Inflammation is also the basis of Central Nervous System (CNS) pathologies, such as Parkinson's and Alzheimer's diseases, characterized by microglia activation and reactive oxygen species (ROS) production. Injection of genetically modified macrophages with an expression vector codifying for high level of catalase, seems to determine a strong reduction of brain inflammation [70]. In particular, Haney et al., using a mouse model of brain inflammation induced by intracranial injections of LPS or 6-hydroxydopamine (6-OHDA), highlighted that macrophage exosomes can cross the blood-brain barrier and transfer the vector, catalase mRNA and protein, to neurons, thus reducing inflammation [70].

\section{Exosomes in oncology}

\subsection{Exosomes as drug delivery system}

Drug toxicity has always represented one of the most critical point of chemotherapeutic treatments with deleterious long- and short-term effects. The debate on the best ways to eliminate or minimize chemotherapy toxicity, treating the lesions selectively, has been going on for years, but a fully satisfying result is still to be found. [76].

Engineered exosomes as therapeutic agents are proving to be a very useful tool for the delivery of therapeutic molecules in different oncological diseases, such as colon carcinoma [77], breast tumour [27, 32, 78, 79], pancreatic adenocarcinoma [80], lung tumour [36] and chronic myeloid leukemia [34]. Many studies demonstrated that natural or engineered exosomes, loaded with chemotherapeutic agents (i.e. imatinib, doxorubicin, or paclitaxel) or macromolecules such as siRNA or miRNA (i.e. Let-7a, BCR-ABL siRNA, miR-134, anti-miR-503, miR$143)$, are able to reduce tumour growth in vivo [32, 34, 78, 81], using far lower concentrations of chemotherapeutic molecules compared to those used for systemic treatments, achieving the same results and avoiding all short- and long-term deleterious effects.

\section{2. miRNA as therapeutic target in osteosarcoma}

It is well- known that miRNAs deregulation can determine tumour development or promote the onset of metastasis, inducing modifications in established tumours. Increasing evidences show an active crosstalk between cancer cells and stromal cells mediated by exosomes, affecting metastatic niche formation and metastatic progression [82, 83]. The role of miRNA present in released exosomes was investigated by Lim et al., who detected that CXCL12 specific miRNAs, transported via exosomes from bone marrow stroma to breast cancer cells, were able to modulate the dormancy of bone metastatic tumour cells [45].

Some researchers used deregulated miRNA not only as possible biomarkers, but also as therapeutic molecules for different cancer diseases. Various deregulated miRNAs were reported to act as both tumour suppressors and oncogenes in osteosarcoma [84]. MiR-326, which regulates BCL-2 expression, is downregulated in osteosarcoma determining enhanced cell survival and inhibition of apoptosis [85], which is associated to tumour progression, metastasis formation and drug resistance [86, 87]. Similarly, tumour suppressor miR-130 is downregulated in osteosarcoma cells [88], while its overexpression is related to the inhibition of cell growth, migration and metastasis formation, interfering with tumour metabolism [88]. Up-regulated miRNAs, also indicated as onco-miRNAs, are associated with tumour development and progression of malignancy, as demonstrated by Lo Dico et al. [89] and Costa et al. [90] in glioma and colon cancer progression respectively. Osteosarcoma cells overexpress miR-300, which acts by targeting bromo-domain-containing protein 7 (BRD7) mRNA, determining cell proliferation and tumour invasion through the induction of Epithelial-Mesenchymal Transition (EMT) [91, 92]. MiR$135 \mathrm{~b}$ is another miRNA implicated in tumour progression and EMT process by targeting the $3^{\prime}$ untranslated regions ( $3^{\prime} \mathrm{UTR}$ ) of large tumour suppressor kinase 2 (LATS2), adenomatous polyposis coli (APC), and glycogen synthase kinase 3 beta (GSK-3 $\beta$ ) mRNAs, resulting in inhibition of expression of these tumour suppressors [93]. 


\section{3. miRNA as therapeutic target in chondrosarcoma}

Numerous deregulated miRNAs have also been correlated to the development of chondrosarcoma, the second most common cancer of the musculoskeletal apparatus, characterized by the abnormal production of cartilage matrix. MiR-30a is a very important tumour suppressor of Sox-4, a factor of SRY-related HMG box (SOX) gene family and runtrelated transcription factor (Runx-2), both implicated in chondrogenesis. In chondrosarcoma, Sox-4 and Runx-2 are up-regulated via inhibition of miR-30a synthesis, whose levels correlate negatively with tumour progression [94, 95]. Another downregulated miRNA implicated in chondrosarcoma is miR-145, which regulates Sox-9 expression, a transcription factor very important in tumour development, not only for chondrosarcoma but also for other tumours. Increased Sox- 9 activities up-regulate ETV-5 transcription factor implicated in EMT process, which induces metastatic formation [96, 97]. Recently, an in vitro study showed that the knockdown of SOX9 by synthetic siRNA, determines cell-cycle arrest and apoptosis, as well as the inhibition of metastasis formation. [98].

All deregulated miRNA identified in these pathologies represent potential targets in therapeutic approaches. However, clinical applications using RNA-based techniques for oncologic diseases have been hindered by the high fragility of these macromolecules, which should be delivered avoiding degradation in order to preserve their therapeutic efficacy. From the publication of the article by El-Andaloussi et al. [30], who firstly public a protocol to produce engineered exosomes to deliver specific siRNA into specific cells, exosomes began to be an important engineering platform, representing a solution for in vivo exogenous RNAs delivery in different models [32, 34, 78, 79, 99]. Among these, the most recent engineered exosomes were made to efficiently deliver BCR-ABL siRNA to chronic myeloid leukemia (CML) cells in order to inhibit cellular growth of Imatinib resistant $\mathrm{K} 562$ cells in an in vivo mouse model [34].

\subsection{Exosomes as miRNA delivery system in osteosarcoma and bone metastasis}

The first attempt of transferring siRNA by exosomes in osteosarcoma cells was carried out by Shimbo et al. [100], who engineered MSCs exosomes introducing miR-143, known to inhibit cells proliferation and migration of osteosarcoma cells. However, their engineered exosomes were able to inhibit migration but not growth of 143B human osteosarcoma cell line, probably because of the low level of delivery [100].

Following El-Andaloussi et al. work [30], various studies tried to improve exosomes delivery through the expression of engineered proteins on the exosomal membrane, whose epitopes are recognised by specific receptors overexpressed in target cells. This strategy aims at increasing the affinity of engineered exosomes to target cells, and to better vehicle chemotherapeutic molecules avoiding aspecific delivery [32, 34, 36, 78, 79, 101]. The encouraging results obtained with exosomes make them attractive also for the management of difficult to treat metastases. Bone metastases from many types of primary tumours, like lung, breast, prostate, kidney, and thyroid cancers, often share the over-expression of some receptors with parental cells. These are usually involved in the events triggering cells metastatic transformation, like epidermal growth factor receptor (EGFR) [102-105]. Tyrosine kinase inhibitors represent the first treatment of tumours with overexpressed EGFR [104, 106], but sometimes they are not effective on metastases that are not sensitive to treatment despite overexpressing the receptor $[104,107]$. In this sense, the use of engineered exosomes to specifically target the receptor seems to be a valid option for the effective treatment of both primary tumour and metastases.

Among various therapeutic applications, new roads are opening for the use of exosomes as biomarkers. In fact, in some clinical studies evaluating the activity of cancer cells- derived exosomes on the modulation of immune system, hypothesize the possibility to use them as biomarkers of chemotherapeutic efficacy (i.e. liquid biopsy), as better reported below.

\section{Exosomes and immune system in musculoskeletal diseases}

The capability of exosomes to modulate the immune system enhancing or suppressing inflammation makes them an attractive candidate as immunotherapy agent [28]. It is well-known that exosomes are able to transport different antigens, loaded onto MHC class I and II complexes, and stimulate immune response through this epitope presented by antigen presenting cells. Dendritic cell (DC)-derived exosomes loaded with viral antigens are capable of activating CD8 + T cells [108], and exosomes from cells of infected tissue that transport bacterial and viral antigens are able to elicit macrophage and determine $\mathrm{T}$ cells activation [109, 110]. Similarly, cancer specific epitopes transported by cancer cells- derived exosomes, after internalization in DC cells, can stimulate cytotoxic T-cells activation against cancer cells. Exploiting this mechanism of action, Yao et al. reported the possible use of cancer cells-derived exosomes as vaccine in CML patients, inducing strong cytotoxic T-cells activity towards CML cells. Furthermore, MSCsderived exosomes presenting cancer-epitopes on their membrane, are able to stimulate the activation of antibody secretion by $B$ cells and induction of Th1 memory cells [111]. The improvement in this topic might lead to the possibility to control all immune regulatory actions of exosomes in degenerative disease, as well as create exosome-based vaccines through bacteria, viruses and cancer cells [112].

\subsection{Exosomes as inflammatory modulator}

Exosomes are important in the regulation of the immune system, not only through a vaccine-like action, but also through inflammatory modulation, which might be useful for some degenerative pathologies such as osteoporosis and arthritis, where alteration of immunologic system and related inflammation status play a crucial role [113, 114]. In these pathologies, pro-inflammatory cytokines have clearly a key role in the activation of osteoclastogenesis and consequently of bone resorption and in the inhibition of osteogenesis and bone formation. For example, Sun et al., used exosomes for curcumin delivery, increasing its solubility, stability, bioavailability and anti-inflammatory effects inside target cells, with the consequent inhibition of IL- 6 and TNF- $\alpha$ secretion as found in an in vivo mouse model, where septic shock was induced through LPS injection [115].

Similarly, exosomes can be used for the delivery of a series of immunomodulator as vitamin D compounds that have immune-regulative effects in osteoporosis [113] or DNA vectors for the expression of antiinflammatory molecules in these pathologies [114]. Exosomes-based immunotherapies might have numerous advantages compared to cellular immunotherapies, considering that their production seems to have a better qualified and especially safer product, without the necessity to preserve cellular viability that represent the greater disadvantage in cell therapy. Furthermore, liposomes or polymeric nanoparticles, currently used to deliver some types of drug molecules, present different problems such as stability, toxicity, other than evading the host immune system. For polymeric nanoparticles, biocompatibility is another problem. Exosomes, by virtue of their natural origin, compared to these systems, are an ideal drug delivery system, with a long half-life, acquired or intrinsic ability to target tissues, high biocompatibility, and minimal or no toxicity issues. In addition, results obtained in exosomebased immune regulations when compared to the problems of those cell-related, foresee the possibility to switch rapidly to an exosomal immunotherapy [116-119].

\section{Conclusions}

The use of exosomes as therapeutic agents is rapidly evolving, showing an enormous potential in various research fields such as 
regenerative medicine and oncology. However, there are still considerable difficulties to overcome to make their use a therapeutic reality. Among these, there is the necessity to standardize manufacturing procedures and the unfavourable ratio between isolation rate and costs. The studies described in this review highlight the great variety of approaches that might be used to modify exosomes and the many therapeutic agents that can be loaded for musculoskeletal diseases treatment. In the field of regenerative medicine, exosomes are still poorly used, although a number of recent studies have shown the potential application of modified exosomes to improve regeneration of different tissues such as bones, nerves and muscles.

A possible limitation of the use of engineered exosomes can be immune reactive actions through exosomes that have different MHC in the membrane respect to host. This problem can easily be overcome using exosome produced by the same host cells, otherwise, immunologically inert exosomes produced by cells cannot have MHC molecules as immature dendritic cells, as suggested in Andaloussi et al. protocol [30].

Conversely, in oncology, exosomes have proven to be a great therapeutic promise, considering their relative easy handling for both their content and targeting to cancer cells. Their small size also allows them to cross barriers that cells or other molecules cannot, and their low immunogenicity makes them suitable as a vehicle for specific drugs, avoiding systemic administration that has deleterious effects [120].

Despite significant advances in the use of exosomes as a vehicle for different chemotherapeutic molecules, to date only one attempt has been made in bone cancers.

Exosomes represent a great promise and new therapeutic area to develop personalized therapeutic carriers as cellular specific delivery of drugs in different pathologies. However, before it can become a therapeutic reality as an effective drug delivery system, the characterization of all their components and their potentially immune actions need to be clearly performed. Moreover, engineering processes should be standardized, to have adequate analytic methods to control exosomes productions in order to ensure a high quality product.

\section{References}

[1] Q. Ge, Y. Zhou, J. Lu, Y. Bai, X. Xie, Z. Lu, miRNA in plasma exosome is stable under different storage conditions, Molecules 19 (2014) 1568-1575.

[2] T.R. Doeppner, J. Herz, A. Görgens, J. Schlechter, A.K. Ludwig, S. Radtke, K. de Miroschedji, P.A. Horn, B. Giebel, D.M. Hermann, Extracellular vesicles improve post-stroke neuroregeneration and prevent postischemic immunosuppression, Stem Cells Transl. Med. 4 (2015) 1131-1143.

[3] D. Furlani, M. Ugurlucan, L. Ong, K. Bieback, E. Pittermann, I. Westien, W. Wang, C. Yerebakan, W. Li, R. Gaebel, R.K. Li, B. Vollmar, G. Steinhoff, N. Ma, Is the intravascular administration of mesenchymal stem cells safe? Mesenchymal stem cells and intravital microscopy, Microvasc. Res. 77 (2009) 370-376.

[4] M. Breitbach, T. Bostani, W. Roell, Y. Xia, O. Dewald, J.M. Nygren, J.W. Fries, K. Tiemann, H. Bohlen, J. Hescheler, A. Welz, W. Bloch, S.E. Jacobsen, B.K. Fleischmann, Potential risks of bone marrow cell transplantation into infarcted hearts, Blood 110 (2007) 1362-1369.

[5] T. Montemurro, M. Viganò, S. Budelli, F. Montelatici, C. Lavazza, L. Marino, V. Parazzi, L. Lazzari, R. Giordano, How we make cell therapy in Italy, Drug Des. Dev. Ther. 9 (2015) 4825-4834.

[6] T. Lener, M. Gimona, L. Aigner, V. Börger, E. Buzas, G. Camussi, N. Chaput, D. Chatterjee, F.A. Court, H.A. Del Portillo, L. O'Driscoll, S. Fais, J.M. FalconPerez, U. Felderhoff-Mueser, L. Fraile, Y.S. Gho, A. Görgens, R.C. Gupta, A. Hendrix, D.M. Hermann, A.F. Hill, F. Hochberg, P.A. Horn, D. de Kleijn, L. Kordelas, B.W. Kramer, E.M. Krämer-Albers, S. Laner-Plamberger, S. Laitinen, T. Leonardi, M.J. Lorenowicz, S.K. Lim, J. Lötvall, C.A. Maguire, A. Marcilla, I. Nazarenko, T. Ochiya, T. Patel, S. Pedersen, G. Pocsfalvi, S. Pluchino, P. Quesenberry, I.G. Reischl, F.J. Rivera, R. Sanzenbacher, K. Schallmoser, I. Slaper-Cortenbach, D. Strunk, T. Tonn, P. Vader, B.W. van Balkom, M. Wauben, S.E. Andaloussi, C. Théry, E. Rohde, B. Giebel, Applying extracellular vesicles based therapeutics in clinical trials - an ISEV position paper, J. Extracell Vesicles. 4 (2015) 30087.

[7] M. Simons, G. Raposo, Exosomes-vesicular carriers for intercellular communication, Curr. Opin. Cell Biol. 21 (2009) 575-581.

[8] L. Raimondi, A. De Luca, N. Amodio, M. Manno, S. Raccosta, S. Taverna, D. Bellavia, F. Naselli, S. Fontana, O. Schillaci, R. Giardino, M. Fini, P. Tassone, A. Santoro, G. De Leo, G. Giavaresi, R. Alessandro, Involvement of multiple myeloma cell-derived exosomes in osteoclast differentiation, Oncotarget 6 (2015) 13772-13789.
[9] T. Thomou, M.A. Mori, J.M. Dreyfuss, M. Konishi, M. Sakaguchi, C. Wolfrum, T.N. Rao, J.N. Winnay, R. Garcia-Martin, S.K. Grinspoon, P. Gorden, C.R. Kahn, Adipose-derived circulating miRNAs regulate gene expression in other tissues, Nature 542 (2017) 450-455.

[10] Z. Andreu, M. Yáñez-Mó, Tetraspanins in extracellular vesicle formation and function, Front. Immunol. 5 (2014) 442.

[11] R. Ghossoub, F. Lembo, A. Rubio, C.B. Gaillard, J. Bouchet, N. Vitale, J. Slavík, M. Machala, P. Zimmermann, Syntenin-ALIX exosome biogenesis and budding into multivesicular bodies are controlled by ARF6 and PLD2, Nat. Commun. 5 (2014) 3477.

[12] Y. Xie, O. Bai, H. Zhang, J. Yuan, S. Zong, R. Chibbar, K. Slattery, M. Qureshi, Y. Wei, Y. Deng, J. Xiang, Membrane-bound HSP70-engineered myeloma cellderived exosomes stimulate more efficient CD8 $(+)$ CTL- and NK-mediated antitumour immunity than exosomes released from heat-shocked tumour cells expressing cytoplasmic HSP70, J. Cell. Mol. Med. 14 (2010) 2655-2666.

[13] N. Vyas, A. Walvekar, D. Tate, V. Lakshmanan, D. Bansal, A. Lo Cicero, G. Raposo, D. Palakodeti, J. Dhawan, Vertebrate Hedgehog is secreted on two types of extracellular vesicles with different signaling properties, Sci. Rep. 4 (2014) 7357.

[14] X. Teng, L. Chen, W. Chen, J. Yang, Z. Yang, Z. Shen, Mesenchymal stem cellderived exosomes improve the microenvironment of infarcted myocardium contributing to angiogenesis and anti-inflammation, Cell. Physiol. Biochem. 37 (2015) 2415-2424.

[15] G. Hu, K.M. Drescher, X.M. Chen, Exosomal miRNAs: biological properties and therapeutic potential, Front. Genet. 3 (2012) 56.

[16] J. Webber, V. Yeung, A. Clayton, Extracellular vesicles as modulators of the cancer microenvironment, Semin. Cell Dev. Biol. 40 (2015) 27-34.

[17] A. Hoshino, B. Costa-Silva, T.L. Shen, G. Rodrigues, A. Hashimoto, M. Tesic Mark, H. Molina, S. Kohsaka, A. Di Giannatale, S. Ceder, S. Singh, C. Williams, N. Soplop, K. Uryu, L. Pharmer, T. King, L. Bojmar, A.E. Davies, Y. Ararso, T. Zhang, H. Zhang, J. Hernandez, J.M. Weiss, V.D. Dumont-Cole, K. Kramer, L.H. Wexler, A. Narendran, G.K. Schwartz, J.H. Healey, P. Sandstrom, K.J. Labori, E.H. Kure, P.M. Grandgenett, M.A. Hollingsworth, M. de Sousa, S. Kaur, M. Jain, K. Mallya, S.K. Batra, W.R. Jarnagin, M.S. Brady, O. Fodstad, V. Muller, K. Pantel, A.J. Minn, M.J. Bissell, B.A. Garcia, Y. Kang, V.K. Rajasekhar, C.M. Ghajar, I. Matei, H. Peinado, J. Bromberg, D. Lyden, Tumour exosome integrins determine organotropic metastasis, Nature 527 (2015) 329-335.

[18] J. Guduric-Fuchs, A. O'Connor, B. Camp, C.L. O'Neill, R.J. Medina, D.A. Simpson, Selective extracellular vesicle-mediated export of an overlapping set of microRNAs from multiple cell types, BMC Genomics 13 (2012) 357.

[19] M.L. Squadrito, C. Baer, F. Burdet, C. Maderna, G.D. Gilfillan, R. Lyle, M. Ibberson, M. De Palma, Endogenous RNAs modulate microRNA sorting to exosomes and transfer to acceptor cells, Cell Rep. 8 (2014) 1432-1446.

[20] B.J. Goldie, M.D. Dun, M. Lin, N.D. Smith, N.M. Verrills, C.V. Dayas, M.J. Cairns, Activity-associated miRNA are packaged in Map1b-enriched exosomes released from depolarized neurons, Nucleic Acids Res. 42 (2014) 9195-9208.

[21] M.J. Shurtleff, M.M. Temoche-Diaz, K.V. Karfilis, S. Ri, R. Schekman, Y-box protein 1 is required to sort microRNAs into exosomes in cells and in a cell-free reaction, elife 5 (2016) 1-23 (e19276).

[22] L. Santangelo, G. Giurato, C. Cicchini, C. Montaldo, C. Mancone, R. Tarallo, C. Battistelli, T. Alonzi, A. Weisz, M. Tripodi, The RNA-binding protein SYNCRIP is a component of the hepatocyte Exosomal machinery controlling MicroRNA sorting, Cell Rep. 17 (2016) 799-808.

[23] C. Hewson, D. Capraro, J. Burdach, N. Whitaker, K.V. Morris, Extracellular vesicle associated long non-coding RNAs functionally enhance cell viability, Noncoding RNA Res. 1 (2016) 3-11.

[24] J. Zhang, S. Li, L. Li, M. Li, C. Guo, J. Yao, S. Mi, Exosome and exosomal microRNA: trafficking, sorting, and function, Genom. Proteom. Bioinform. 13 (2015) 17-24.

[25] S. Keller, J. Ridinger, A.K. Rupp, J.W. Janssen, P. Altevogt, Body fluid derived exosomes as a novel template for clinical diagnostics, J. Transl. Med. 9 (2011) 86

[26] K.J. Svensson, H.C. Christianson, A. Wittrup, E. Bourseau-Guilmain, E. Lindqvist, L.M. Svensson, M. Mörgelin, M. Belting, Exosome uptake depends on ERK1/2-hea shock protein 27 signaling and lipid raft-mediated endocytosis negatively regulated by caveolin-1, J. Biol. Chem. 288 (2013) 17713-17724.

[27] T. Tian, Y.L. Zhu, Y.Y. Zhou, G.F. Liang, Y.Y. Wang, F.H. Hu, Z.D. Xiao, Exosome uptake through clathrin-mediated endocytosis and macropinocytosis and mediating miR-21 delivery, J. Biol. Chem. 289 (2014) 22258-22267.

[28] P.D. Robbins, A.E. Morelli, Regulation of immune responses by extracellular vesicles, Nat. Rev. Immunol. 14 (2014) 195-208.

[29] L. Alvarez-Erviti, Y. Seow, H. Yin, C. Betts, S. Lakhal, M.J. Wood, Delivery of siRNA to the mouse brain by systemic injection of targeted exosomes, Nat. Biotechnol. 29 (2011) 341-345.

[30] S. El-Andaloussi, Y. Lee, S. Lakhal-Littleton, J. Li, Y. Seow, C. Gardiner, L. Alvarez Erviti, I.L. Sargent, M.J. Wood, Exosome-mediated delivery of siRNA in vitro and in vivo, Nat. Protoc. 7 (2012) 2112-2126.

[31] Y. Akao, A. Iio, T. Itoh, S. Noguchi, Y. Itoh, Y. Ohtsuki, T. Naoe, Microvesiclemediated RNA molecule delivery system using monocytes/macrophages, Mol, Ther. 19 (2011) 395-399.

[32] S. Ohno, M. Takanashi, K. Sudo, S. Ueda, A. Ishikawa, N. Matsuyama, K. Fujita, T. Mizutani, T. Ohgi, T. Ochiya, N. Gotoh, M. Kuroda, Systemically injected exosomes targeted to EGFR deliver antitumor MicroRNA to breast Cancer cells, Mol. Ther. 21 (2013) 185-191.

[33] Y. Liu, D. Li, Z. Liu, Y. Zhou, D. Chu, X. Li, X. Jiang, D. Hou, X. Chen, Y. Chen, Z. Yang, L. Jin, W. Jiang, C. Tian, G. Zhou, K. Zen, J. Zhang, Y. Zhang, J. Li, C.Y. Zhang, Targeted exosome-mediated delivery of opioid receptor Mu siRNA for the treatment of morphine relapse, Sci. Rep. 5 (2015) 17543. 
[34] D. Bellavia, S. Raimondo, G. Calabrese, S. Forte, M. Cristaldi, A. Patinella, L. Memeo, M. Manno, S. Raccosta, P. Diana, G. Cirrincione, G. Giavaresi, F. Monteleone, S. Fontana, G. De Leo, R. Alessandro, Interleukin 3- receptor targeted exosomes inhibit in vitro and in vivo chronic myelogenous leukemia cell growth, Theranostics 7 (2017) 1333-1345.

[35] H. Saari, E. Lazaro-Ibanez, T. Viitala, E. Vuorimaa-Laukkanen, P. Siljander, M. Yliperttula, Microvesicle- and exosome-mediated drug delivery enhances the cytotoxicity of Paclitaxel in autologous prostate cancer cells, J. Control. Release 220 (2015) 727-737.

[36] M.S. Kim, M.J. Haney, Y. Zhao, V. Mahajan, I. Deygen, N.L. Klyachko, E. Inskoe, A. Piroyan, M. Sokolsky, O. Okolie, S.D. Hingtgen, A.V. Kabanov, E.V. Batrakova, Development of exosome-encapsulated paclitaxel to overcome MDR in cancer cells, Nanomedicine 12 (2016) 655-664.

[37] J.J. Alm, H.M. Koivu, T.J. Heino, T.A. Hentunen, S. Laitinen, H.T. Aro, Circulating plastic adherent mesenchymal stem cells in aged hip fracture patients, J. Orthop. Res. 28 (2010) 1634-1642.

[38] J. Deng, Z.M. Zou, T.L. Zhou, Y.P. Su, G.P. Ai, J.P. Wang, H. Xu, S.W. Dong, Bone marrow mesenchymal stem cells can be mobilized into peripheral blood by G-CSF in vivo and integrate into traumatically injured cerebral tissue, Neurol. Sci. 32 (2011) 641-651.

[39] R. Schäfer, G. Spohn, P.C. Baer, Mesenchymal stem/stromal cells in regenerative medicine: can preconditioning strategies improve therapeutic efficacy? Transfus. Med. Hemother. 43 (2016) 256-267.

[40] T.N. Lamichhane, S. Sokic, J.S. Schardt, R.S. Raiker, J.W. Lin, S.M. Jay, Emerging roles for extracellular vesicles in tissue engineering and regenerative medicine, Tissue Eng Part B Rev. 21 (2015) 45-54.

[41] H. Xin, Y. Li, B. BulleR, M. Katakowski, Y. Zhang, X. Wang, X. Shang, Z.G. Zhang, M. Chopp, Exosome-mediated transfer of miR-133b from multipotent mesenchymal stromal cells to neural cells contributes to neurite outgrowth, Stem Cells 30 (2012) 1556-1564.

[42] M.J. Haney, Y. Zhao, E.B. Harrison, V. Mahajan, S. Ahmed, Z. He, P. Suresh, S.D. Hingtgen, N.L. Klyachko, R.L. Mosley, H.E. Gendelman, A.V. Kabanov, E.V. Batrakova, Specific transfection of inflamed brain by macrophages: a new therapeutic strategy for neurodegenerative diseases, PLoS One 8 (2013) e61852.

[43] J.M. Karp, G.S. Leng Teo, Mesenchymal stem cell homing: the devil is in the details, Cell Stem Cell (3) (2009) 206-216.

[44] R.C. Lai, F. Arslan, M.M. Lee, N.S. Sze, A. Choo, T.S. Chen, M. Salto-Tellez, L. Timmers, C.N. Lee, R.M. El Oakley, G. Pasterkamp, D.P. de Kleijn, S.K. Lim, Exosome secreted by MSC reduces myocardial ischemia/reperfusion injury, Stem Cell Res. (3) (2010) 214-222.

[45] P.K. Lim, S.A. Bliss, S.A. Patel, M. Taborga, M.A. Dave, L.A. Gregory, S.J. Greco, M. Bryan, P.S. Patel, P. Rameshwar, Gap junction-mediated import of microRNA from bone marrow stromal cells can elicit cell cycle quiescence in breast cancer cells, Cancer Res. 71 (2011) 1550-1560

[46] M. Morigi, B. Imberti, C. Zoja, D. Corna, S. Tomasoni, M. Abbate, D. Rottoli, S. Angioletti, A. Benigni, N. Perico, M. Alison, G. Remuzzi, Mesenchymal stem cells are renotropic, helping to repair the kidney and improve function in acute renal failure, J. Am. Soc. Nephrol. 7 (2004) 1794-1804.

[47] F. Lin, A. Moran, P. Igarashi, Intrarenal cells, not bone marrow-derived cells, are the major source for regeneration in postischemic kidney, J. Clin. Investig. (7) (2005) 1756-1764.

[48] B. Bi, R. Schmitt, M. Israilova, H. Nishio, L.G. Cantley, Stromal cells protect against acute tubular injury via an endocrine effect, J. Am. Soc. Nephrol. (9) (2007) 2486-2496.

[49] L.A. Reis, F.T. Borges, M.J. Simões, A.A. Borges, R. Sinigaglia-Coimbra, N. Schor, Bone marrow-derived mesenchymal stem cells repaired but did not prevent gentamicin-induced acute kidney injury through paracrine effects in rats, PLoS One (9) (2012) e44092.

[50] Y. Qin, R. Sun, C. Wu, L. Wang, C. Zhang, Exosome: a novel approach to stimulate bone regeneration through regulation of osteogenesis and angiogenesis, Int. J. Mol. Sci. 17 (2016) pii: E712.

[51] J.F. Xu, G.H. Yang, X.H. Pan, S.J. Zhang, C. Zhao, B.S. Qiu, H.F. Gu, J.F. Hong, L. Cao, Y. Chen, B. Xia, Q. Bi, Y.P. Wang, Altered microrna expression profile in exosomes during osteogenic differentiation of human bone marrow-derived mesenchymal stem cells, PLoS One 9 (2014) e114627.

[52] R. Narayanan, C.C. Huang, S. Ravindran, Hijacking: The cellular mail: exosome mediated differentiation of mesenchymal stem cells, Stem Cells Int. 2016 (2016) 3808674

[53] T. Furuta, S. Miyaki, H. Ishitobi, T. Ogura, Y. Kato, N. Kamei, K. Miyado, Y. Higashi, M. Ochi, Mesenchymal stem cell-derived exosomes promote fracture healing in a mouse model, Stem Cells Transl. Med. 5 (2016) 1620-1630.

[54] M. Martins, D. Ribeiro, A. Martins, R.L. Reis, N.M. Neves, Extracellular vesicles derived from osteogenically induced human bone marrow mesenchymal stem cells can modulate lineage commitment, Stem Cell Rep. 6 (2016) 284-291.

[55] Y. Cui, J. Luan, H. Li, X. Zhou, J. Han, Exosomes derived from mineralizing osteoblasts promote ST2 cell osteogenic differentiation by alteration of microrn expression, FEBS Lett. 590 (2016) 185-192.

[56] V. Costa, L. Raimondi, A. Conigliaro, F. Salamanna, V. Carina, A. De Luca, D. Bellavia, R. Alessandro, M. Fini, G. Giavaresi, Hypoxia-inducible factor 1A may regulate the commitment of mesenchymal stromal cells toward angio-osteogenesis by mirna-675-5P, Cytotherapy S1465-3249 (2017) 30706-5.

[57] D. Li, J. Liu, B. Guo, C. Liang, L. Dang, C. Lu, X. He, H.Y. Cheung, L. Xu, C. Lu, B. He, B. Liu, A.B. Shaikh, F. Li, L. Wang, Z. Yang, D.W. Au, S. Peng, Z. Zhang, B.T. Zhang, X. Pan, A. Oian, P. Shang, L. Xiao, B. Jiang, C.K. Wong, J. Xu, Z. Bian, Z. Liang, D.A. Guo, H. Zhu, W. Tan, A. Lu, G. Zhang, Osteoclast-derived exosomal miR-214-3p inhibits osteoblastic bone formation, Nat. Commun. 7 (2016) 10872
[58] E.E. Golub, Biomineralization and matrix vesicles in biology and pathology, Semin. Immunopathol. 33 (2011) 409-417.

[59] K. Ekstrom, O. Omar, C. Graneli, X. Wang, F. Vazirisani, P. Thomsen, Monocyte exosomes stimulate the osteogenic gene expression of mesenchymal stem cells, PLoS One 8 (2013) e75227.

[60] L. da S. Meirelles, A.M. Fontes, D.T. Covas, A.I. Caplan, Mechanisms involved in the therapeutic properties of mesenchymal stem cells, Cytokine Growth Factor Rev. 20 (2009) 419-427.

[61] W.S. Toh, C.B. Foldager, M. Pei, J.H.P. Hui, Advances in mesenchymal stem cellbased strategies for cartilage repair and regeneration, Stem Cell Rev. 10 (2014) 686-696.

[62] B. Zhang, Y. Yin, R.C. Lai, S.S. Tan, A.B. Choo, S.K. Lim, Mesenchymal stem cells secrete immunologically active exosomes, Stem Cells Dev. 23 (2014) 1233-1244.

[63] S. Zhang, W.C. Chu, R.C. Lai, S.K. Lim, J.H. Hui, W.S. Toh, Exosomes derived fron human embryonic mesenchymal stem cells promote osteochondral regeneration, Osteoarthr. Cartil. 24 (2016) 2135-2140.

[64] W.S. Toh, R.C. Lai, J.H.P. Hui, S.K. Lim, MSC exosome as a cell-free MSC therapy for cartilage regeneration: implications for osteoarthritis treatment, Semin. Cell Dev. Biol. 67 (2017) 56-64.

[65] S.H. Kim, N. Bianco, R. Menon, E.R. Lechman, W.J. Shufesky, A.E. Morelli, P.D. Robbins, Exosomes derived from genetically modified dc expressing fasl are anti-inflammatory and immunosuppressive, Mol. Ther. 13 (2006) 289-300.

[66] S.H. Kim, N.R. Bianco, W.J. Shufesky, A.E. Morelli, P.D. Robbins, Effective treatment of inflammatory disease models with exosomes derived from dendritic cells genetically modified to express IL-4, J. Immunol. 179 (2007) 2242-2249.

[67] J.A. Chan, A.M. Krichevsky, K.S. Kosik, MicroRNA-21 is an antiapoptotic factor in human glioblastoma cells, Cancer Res. 65 (2005) 6029-6033.

[68] T. Nakasa, M. Ishikawa, M. Shi, H. Shibuya, N. Adachi, M. Ochi, Acceleration of muscle regeneration by local injection of muscle-specific microRNAs in rat skeletal muscle injury model, J. Cell. Mol. Med. 14 (2010) 2495-2505.

[69] Y. Nakamura, S. Miyaki, H. Ishitobi, S. Matsuyama, T. Nakasa, N. Kamei, T. Akimoto, Y. Higashi, M. Ochi, Mesenchymal-stem-cell-derived exosomes accelerate skeletal muscle regeneration, FEBS Lett. 589 (2015) 1257-1265.

[70] M.J. Haney, N.L. Klyachko, Y. Zhao, R. Gupta, E.G. Plotnikova, Z. He, T. Patel, A. Piroyan, M. Sokolsky, A.V. Kabanov, E.V. Batrakova, Exosomes as drug delivery vehicles for Parkinson's disease therapy, J. Control. Release 207 (2015) 18-30.

[71] J. Casañas, J. de la Torre, F. Soler, F. García, C. Rodellar, M. Pumarola, J. Climent, R. Soler, L. Orozco, Peripheral nerve regeneration after experimental section in ovine radial and tibial nerves using synthetic nerve grafts, including expanded bone marrow mesenchymal cells: morphological and neurophysiological results, Injury 45 (2014) S2-S6.

[72] J.T. Oliveira, R.E. Bittencourt-Navarrete, F.M. de Almeida, C. Tonda-Turo, A.M.B. Martinez, J.G. Franca, Enhancement of median nerve regeneration by mesenchymal stem cells engraftment in an absorbable conduit: improvement of peripheral nerve morphology with enlargement of somatosensory cortical representation, Front. Neuroanat. 8 (2014) 111.

[73] T. Tamaki, Bridging long gap peripheral nerve injury using skeletal muscle-derived multipotent stem cells, Neural Regen. Res. 9 (2014) 1333-1336.

[74] A. Carrier-Ruiz, F. Evaristo-Mendonça, R. Mendez-Otero, V. Ribeiro-Resende, Biological behavior of mesenchymal stem cells on poly-epsiloncaprolactone filaments and a strategy for tissue engineering of segments of the peripheral nerves, Stem Cell Res Ther 6 (2015) 128.

[75] L.P. Cartarozzi, A.B. Spejo, R.S. Jr Ferreira, B. Barraviera, E. Duek, J.L. Carvalho, A.M. Góes, A.L. Oliveira, Mesenchymal stem cells engrafted in a fibrin scaffold stimulate Schwann cell reactivity and axonal regeneration following sciatic nerve tubulization, Brain Res. Bull. 112 (2015) 14-24.

[76] S. Perry, Reduction of toxicity in cancer chemotherapy, Cancer Res. 29 (1969) 2319-2325.

[77] Y. Akao, Y. Nakagawa, I. Hirata, A. Iio, T. Itoh, K. Kojima, R. Nakashima, Y. Kitade, T. Naoe, Role of anti-oncomirs miR-143 and -145 in human colorectal tumors, Cancer Gene Ther. 17 (2010) 398-408.

[78] K. O'Brien, M.C. Lowry, C. Corcoran, V.G. Martinez, M. Daly, S. Rani, W.M. Gallagher, M.W. Radomski, R.A. MacLeod, L. O'Driscoll, miR-134 in extracellular vesicles reduces triple-negative breast cancer aggression and increases drug sensitivity, Oncotarget 6 (2015) 32774-32789.

[79] N. Bovy, B. Blomme, P. Freres, S. Dederen, O. Nivelles, M. Lion, O. Carnet, J.A. Martial, A. Noel, M. Thiry, G. Jérusalem, C. Josse, V. Bours, S.P. Tabruyn, I. Struman, Endothelial exosomes contribute to the antitumor response during breast cancer neoadjuvant chemotherapy via microRNA transfer, Oncotarget 6 (2015) 10253-10266.

[80] L. Pascucci, V. Coccè, A. Bonomi, D. Ami, P. Ceccarelli, E. Ciusani, L. Viganò, A. Locatelli, F. Sisto, S.M. Doglia, E. Parati, M.E. Bernardo, M. Muraca, G. Alessandri, G. Bondiolotti, A. Pessina, Paclitaxel is incorporated by mesenchymal stromal cells and released in exosomes that inhibit in vitro tumor growth: new approach for drug delivery, J. Control. Release 192 (2014) 262-270.

[81] P. Vader, X.O. Breakefield, M.J. Wood, Extracellular vesicles: emerging targets for cancer therapy, Trends Mol. Med. 20 (2014) 385-393.

[82] R.M. Hoffman, Stromal-cell and cancer-cell exosomes leading the metastatic exodus for the promised niche, Breast Cancer Res. 15 (2013) 310.

[83] V. Luga, L. Zhang, A.M. Viloria-Petit, A.A. Ogunjimi, M.R. Inanlou, E. Chiu, M. Buchanan, A.N. Hosein, M. Basik, J.L. Wrana, Exosomes mediate stromal mobilization of autocrine Wnt-PCP signaling in breast cancer cell migration, Cell 15 (2012) 1542-1556.

[84] L. Raimondi, A. De Luca, V. Costa, N. Amodio, V. Carina, D. Bellavia, P. Tassone, S. Pagani, M. Fini, R. Alessandro, G. Giavaresi, Circulating biomarkers in osteosarcoma: new translational tools for diagnosis and treatment, Oncotarget 8 (2017) 
$100831-100851$

[85] L. Cao, J. Wang, P.Q. Wang, MiR-326 is a diagnostic biomarker and regulates cell survival and apoptosis by targeting Bcl-2 in osteosarcoma, Biomed Pharmacother 84 (2016) 828-835.

[86] Z. Liang, H. Wu, J. Xia, Y. Li, Y. Zhang, K. Huang, N. Wagar, Y. Yoon, H.T. Cho, S. Scala, H. Shim, Involvement of miR-326 in chemotherapy resistance of breast cancer through modulating expression of multidrug resistance-associated protein 1, Biochem. Pharmacol. 79 (2010) 817-824.

[87] K. Valencia, M. Martin-Fernandez, C. Zandueta, C. Ormazabal, S. MartinezCanarias, E. Bandres, C. de la Piedra, F. Lecanda, miR-326 associates with biochemical markers of bone turnover in lung cancer bone metastasis, Bone 52 (2013) 532-539.

[88] L. Yi, M. Liu, Z. Tang, MicroRNA-130a inhibits growth and metastasis of osteosarcoma cells by directly targeting ZEB1, Mol. Med. Rep. 16 (2017) 3606-3612.

[89] A. Lo Dico, V. Costa, C. Martelli, C. Diceglie, F. Rajata, A. Rizzo, C. Mancone, M. Tripodi, L. Ottobrini, R. Alessandro, A. Conigliaro, MiR675-5p acts on HIF-1a; to sustain hypoxic responses: a new terapeutic strategy for glioma, Theranostics 6 (2016) 1105-1118.

[90] V. Costa, A. Lo Dico, A. Rizzo, F. Rajata, M. Tripodi, R. Alessandro, A. Conigliaro, MiR-675-5p supports hypoxia induced epithelial to mesenchymal transition in colon cancer cells, Oncotarget 8 (2017) 24292-24302.

[91] J. Yu, F. Xie, X. Bao, W. Chen, O. Xu, miR-300 inhibits epithelial to mesenchymal transition and metastasis by targeting twist in human epithelial cancer, Mol. Cancer 13 (2014) 121

[92] Z. Xue, J. Zhao, L. Niu, G. An, Y. Guo, L. Ni, Up-regulation of MiR-300 promotes proliferation and invasion of osteosarcoma by targeting BRD7, PLoS One 10 (2015) e0127682.

[93] S. Shen, K. Huang, Y. Wu, Y. Ma, J. Wang, F. Qin, J. Ma, A miR-135b-TAZ positive feedback loop promotes epithelial-mesenchymal transition (EMT) and tumorigenesis in osteosarcoma, Cancer Lett. 407 (2017) 32-44.

[94] N. Lu, T. Lin, L. Wang, M. Qi, Z. Liu, H. Dong, X. Zhang, C. Zhai, Y. Wang, L. Liu, L. Xiang, L. Qi, B. Han, J. Li, Association of SOX4 regulated by tumor suppresso miR-30a with poor prognosis in low-grade chondrosarcoma, Tumour Biol. 36 (2015) 3843-3852.

[95] X.C. Jiang, J.Q. Gao, Exosomes as novel bio-carriers for gene and drug delivery, Int. J. Pharm. 521 (2017) 167-175.

[96] P.F. Power, I.W. Mak, S. Singh, S. Popovic, R. Gladdy, M. Ghert, ETV5 as a regulator of matrix metalloproteinase 2 in human chondrosarcoma, J. Orthop. Res. 31 (2013) 493-501.

[97] I.W.Y. Mak, S. Singh, R. Turcotte, M. Ghert, The epigenetic regulation of SOX9 by miR-145 in human chondrosarcoma, J. Cell. Biochem. 116 (2015) 37-44.

[98] H. Chen, C.C. Garbutt, D. Spentzos, E. Choy, F.J. Hornicek, Z. Duan, Expression and therapeutic potential of SOX9 in Chordoma, Clin. Cancer Res. 23 (2017) $5176-5186$.

[99] T.R. Lunavat, S.C. Jang, L. Nilsson, H.T. Park, G. Repiska, C. Lasser, J.A. Nilsson, Y.S. Gho, J. Lotvall, RNAi delivery by exosome-mimetic nanovesicles-implications for targeting c-Myc in cancer, Biomaterials 102 (2016) 231-238.

[100] K. Shimbo, S. Miyaki, H. Ishitobi, Y. Kato, T. Kubo, S. Shimose, M. Ochi, Exosomeformed synthetic microRNA-143 is transferred to osteosarcoma cells and inhibits their migration, Biochem. Biophys. Res. Commun. 445 (2014) 381-387.

[101] Y. Tian, S. Li, J. Song, T. Ji, M. Zhu, G.J. Anderson, J. Wei, G. Nie, A doxorubicin delivery platform using engineered natural membrane vesicle exosomes for targeted tumor therapy, Biomaterials 35 (2014) 2383-2390.

[102] V. Bossuyt, O. Fadare, M. Martel, I.T. Ocal, B. Burtness, F. Moinfar, S. Leibl, F.A. Tavassoli, Remarkably high frequency of EGFR expression in breast carcinomas with squamous differentiation, Int. J. Surg. Pathol. 13 (2005) 319-327.

[103] M.N. Younes, O.G. Yigitbasi, Y.W. Park, S.J. Kim, S.A. Jasser, V.S. Hawthorne, Y.D. Yazici, M. Mandal, B.N. Bekele, C.D. Bucana, I.J. Fidler, J.N. Myers, Antivascular therapy of human follicular thyroid cancer experimental bone metastasis by blockade of epidermal growth factor receptor and vascular growth factor receptor phosphorylation, Cancer Res. 65 (2005) 4716-4727.

[104] X. Lu, Q. Wang, G. Hu, C. Van Poznak, M. Fleisher, M. Reiss, J. Massagué, Y. Kang, ADAMTS1 and MMP1 proteolytically engage EGF-like ligands in an osteolytic signaling cascade for bone metastasis, Genes Dev. 23 (2009) 1882-1894.

[105] K.C. Day, G.L. Hiles, M. Kozminsky, S.J. Dawsey, A. Paul, L.J. Broses, R. Shah, L.P. Kunja, C. Hall, N. Palanisamy, S. Daignault-Newton, L. El-Sawy, S.J. Wilson, A. Chou, K.W. Ignatoski, E. Keller, D. Thomas, S. Nagrath, T. Morgan, M.L. Day, HER2 and EGFR overexpression support metastatic progression of prostate Cancer to bone, Cancer Res. 77 (2017) 74-85.

[106] M.H. Massicotte, M. Brassard, M. Claude-Desroches, I. Borget, F. Bonichon, A.L. Giraudet, C. Do Cao, C.N. Chougnet, S. Leboulleux, E. Baudin, M. Schlumberger, C. de la Fouchardière, C. Tyrosine kinase inhibitor treatments in patients with metastatic thyroid carcinomas: a retrospective study of the TUTHYREF network, Eur. J. Endocrinol. 170 (2014) 575-582.

[107] M.K. Siu, W. Abou-Kheir, J.J. Yin, Y.S. Chang, B. Barrett, F. Suau, O. Casey, W.Y. Chen, L. Fang, P. Hynes, Y.Y. Hsieh, Y.N. Liu, J. Huang, K. Kelly, Loss of EGFR signaling regulated miR-203 promotes prostate cancer bone metastasis and tyrosine kinase inhibitors resistance, Oncotarget 5 (2014) 3770-3784.

[108] C. Admyre, S.M. Johansson, S. Paulie, S. Gabrielsson, Direct exosome stimulation of peripheral human T cells detected by ELISPOT, Eur. J. Immunol. 36 (2006) $1772-1781$.

[109] S. Bhatnagar, J.S. Schorey, Exosomes released from infected macrophages contain Mycobacterium avium glycopeptidolipids and are proinflammatory, J. Biol. Chem. 282 (2007) 25779-25789.

[110] J.D. Walker, C.L. Maier, J.S. Pober, Cytomegalovirus-infected human endothelia cells can stimulate allogeneic CD4+ memory T cells by releasing antigenic exosomes, J. Immunol. 182 (2009) 1548-1559.

[111] K.R. Qazi, U. Gehrmann, E. Domange Jordö, M.C. Karlsson, S. Gabrielsson, Antigen-loaded exosomes alone induce Th1-type memory through a B-cell-dependent mechanism, Blood 113 (2009) 2673-2683.

[112] U. Gehrmann, T.I. Näslund, S. Hiltbrunner, P. Larssen, S. Gabrielsson, Harnessing the exosome-induced immune response for cancer immunotherapy, Semin. Cance Biol. 28 (2014) 58-67.

[113] D. Bellavia, V. Costa, A. De Luca, M. Maglio, S. Pagani, M. Fini, G. Giavaresi, D. Vitamin, Level between calcium-phosphorus homeostasis and immune system: new perspective in osteoporosis, Curr. Osteoporos. Rep. (2016 Oct 13) 1-12 [Epub ahead of print] https://doi.org/10.1007/s11914-016-0331-2.

[114] D. Bellavia, F. Veronesi, V. Carina, V. Costa, L. Raimondi, A. De Luca, R. Alessandro, M. Fini, G. Giavaresi, Gene therapy for chondral and osteochondral regeneration: is the future now? Cell. Mol. Life Sci. 75 (2017) 649-667.

[115] D. Sun, X. Zhuang, X. Xiang, Y. Liu, S. Zhang, C. Liu, S. Barnes, W. Grizzle, D. Miller, H.G. Zhang, A novel nanoparticle drug delivery system: the anti-inflammatory activity of curcumin is enhanced when encapsulated in exosomes, Mol. Ther. 18 (2010) 1606-1614.

[116] C. Beauvillain, S. Ruiz, R. Guiton, D. Bout, I. Dimier-Poisson, A vaccine based on exosomes secreted by a dendritic cell line confers protection against T. Gondii infection in syngeneic and allogeneic mice, Microbes Infect. 9 (2007) 1614-1622.

[117] J.M. Pitt, M. Charrier, S. Viaud, F. André, B. Besse, N. Chaput, L. Zitvogel, Dendritic cell-derived exosomes as immunotherapies in the fight against cancer, $\mathrm{J}$. Immunol. 193 (2014) 1006-1011.

[118] Y. Yao, C. Wang, W. Wei, C. Shen, X. Deng, L. Chen, L. Ma, S. Hao, Dendritic cells pulsed with leukemia cell-derived exosomes more efficiently induce antileukemic immunities, PLoS One 9 (2014) e91463.

[119] T.H. Tran, G. Mattheolabakis, H. Aldawsari, M. Amiji, Exosomes as nanocarriers for immunotherapy of cancer and inflammatory diseases, Clin. Immunol. 160 (2015) 46-58.

[120] H. Ma, C. He, Y. Cheng, Z. Yang, J. Zang, J. Liu, X. Chen, Localized co-delivery of doxorubicin, cisplatin, and methotrexate by thermosensitive hydrogels for enhanced osteosarcoma treatment, ACS Appl. Mater. Interfaces 7 (2015) 27040-27048. 